\title{
EVALUASI PENERAPAN SKEMA PPH 25 ATAS WAJIB PAJAK ORANG PRIBADI PENGUSAHA TERTENTU SESUAI PP NOMOR 23 TAHUN 2018 DALAM UPAYA PENINGKATAN KEPATUHAN PERPAJAKAN PADA UMKM KOTA TANGERANG SELATAN
}

\author{
Budi Setyawan \\ Email :dosen01453@unpam.ac.id \\ Prodi Akuntansi D3/Fakutas Ekonomi/Universitas Pamulang \\ Jl.Surya Kencana No.1, Tangerang Selatan \\ Sukarno \\ Email : dosen01565@unpam.ac.id \\ Prodi Akuntansi D3/Fakutas Ekonomi/Universitas Pamulang \\ Jl.Surya Kencana No.1, Tangerang Selatan
}

\begin{abstract}
ABSTRAK
Penelitian ini bertujuan untuk mengevaluasi kepatuhan perpajakan Wajib Pajak Orang Pribadi (WPOP) Pengusaha Tertentu yang menggunakan tarif pajak umum yaitu PPh 25 dengan tarif 0,75\% yang dapat dikreditkan di akhir tahun pajak, sehubungan dengan adanya penurunan tarif PPh Final dari 1\% menjadi 0,5\% dengan diterbitkannya Peraturan Pemerintah (PP) Nomor 23 tahun 2018. Wajib Pajak Orang Pribadi (WPOP) Pengusaha Tertentu juga dipersiapkan untuk lebih tertib dan disiplin dalam menyelenggarakan pembukuan untuk menyusun laporan keuangannya agar dapat menentukan pajak terutang menggunakan skema PPh 25 dengan lebih tepat. Terutama bagi WPOP Pengusaha Tertentu yang sudah memiliki omzet lebih dari Rp 4.800.000.000,- (Empat Milyar Delapan Ratus Juta Rupiah) dalam satu tahun pajak. Metode yang digunakan adalah Metode Studi Lapangan (Field Research) dengan terjun langsung ke lapangan. Data penelitian diperoleh observasi, dokumentasi dan wawancara langsung para pelaku UMKM Wajib Pajak Orang Pribadi (WPOP) Pengusaha Tertentu di Kota Tangerang Selatan dan melalui data sekunder melalui studi literatur. Jenis penelitian ini adalah penelitian deskriptif kualitatif. Peneliti menggunakan metode penelitian deskriptif kualitatif karena penelitian ini mengeksplor fenomena peningkatan kepatuhan perpajakan dan proses penyusunan pembukuan para pelaku UMKM WPOP Pengusaha Tertentu di Kota Tangerang Selatan. Hasil penelitian menunjukkan Penerapan Skema PPh Pasal 25 Atas WPOP Pengusaha Tertentu sesuai PP Nomor 23 Tahun 2018 pada UMKM Kota Tangerang Selatan yang terdaftar di KPP Pratama Serpong dan KPP Pratama Pondok Aren tidak maksimal karena wajib pajak cenderung menggunakan tarif PPh Final 0,5\% dan tidak efektif dalam meningkatkan tingkat kepatuhan WPOP Pengusaha Tertentu.
\end{abstract}

Kata Kunci: PPh 25, PPh Final, Kepatuhan, dan UMKM

\begin{abstract}
This study aims to evaluate the tax compliance of certain individual taxpayers (WPOP) using general tax rates, namely $\mathrm{PPh} 25$ at a rate of $0.75 \%$, which can be credited at the end of the tax year, in connection with a reduction in the Final Income Tax rate from $1 \%$ to $0 ., 5 \%$ with the issuance of Government Regulation (PP) Number 23 of 2018. Individual Taxpayers (WPOP) Certain Entrepreneurs are also prepared to be more orderly and disciplined in keeping track of their financial statements to determine payable taxes using the PPh 25 scheme more precisely. Especially for Certain Entrepreneur WPOPs who already have a turnover of more than IDR 4,800,000,000 - (Four Billion Eight Hundred Million Rupiah) in one tax year. The method used is the Field Research Method by going directly to the field. Research data is obtained by observation, documentation, and direct
\end{abstract}


interviews of SME actors Individual Taxpayers (WPOP), Certain Entrepreneurs in South Tangerang City, and secondary data through literature studies. This type of research is a qualitative descriptive study. The researcher uses a qualitative descriptive research method because it explores the phenomenon of increasing tax compliance and the bookkeeping process of individual entrepreneurs in South Tangerang. The results showed that the application of the PPh Article 25 Scheme on the WPOP of Certain Entrepreneurs by Government Regulation Number 23 of 2018 at South Tangerang City MSMEs registered at KPP Pratama Serpong and KPP Pratama Pondok Aren is not optimal because taxpayers tend to use a Final PPh rate of $0.5 \%$ and not. Useful in increasing the level of compliance of certain employers' WPOP.

Keywords: PPh 25, Final Income Tax, Compliance, and MSMEs.

\section{PENDAHULUAN}

Sumbangan Usaha Mikro, Kecil dan Menengah (UMKM) terhadap output nasional (PDRB) sebesar 56,7 persen, UMKM juga memberikan kontribusi sekitar 99 persen dalam jumlah badan usaha di Indonesia serta mempunyai andil 99,6 persen dalam penyerapan tenaga kerja. Pengembangan Usaha Kecil dan Menengah juga perlu lebih diperhatikan karena mengemban misi menciptakan pemerataan kesempatan kerja dan berusaha, melestarikan budaya, dan mendukung ekspor nasional (Goso \& Bachri, 2015), selain itu lingkungan bisnis sangat dinamis dan kompetitif, sehingga UMKM dituntut untuk mampu beradaptasi, memiliki agility agar meraih keunggulan kompetitif yang berkelanjutan (Suci, Hermawati, \& Suwarta, 2019).

Menurut Direktorat Jenderal Pajak (Ditjen Pajak) Kementerian Keuangan menyatakan, sampai dengan saat ini masih sedikit pelaku Usaha Mikro, Kecil, Menengah (UMKM) yang terdaftar sebagai wajib pajak. Setidaknya ada 1,8 juta pelaku UMKM wajib pajak yang terdaftar hingga 2019 (Movanita, 2019). Masih banyak pelaku UMKM yang belum memiliki kepatuhan dalam melaksanakan kewajiban perpajakannya. Untuk meningkatkan kepatuhan perpajakan dari para pelaku UMKM maka pemerintah menerbitkan PP No. 23 tahun 2018 yang menurunkan tarif Pajak Penghasilan (PPh) Final UMKM dari 1\% menjadi 0.5\%, yang berlaku mulai 1 Juli 2018.

Pemerintah perlu memberikan perhatian yang lebih terhadap peningkatan pertumbuhan UMKM, hal ini sesuai dengan penelitian (Ikbal, Mustafa, \& Bustami, 2018) dengan menurunnya Usaha Mikro, Kecil dan Menengah begitu pula Pengangguran di Kota Palopo akan meningkat diikuti dengan perubahan peningkatan signifikan. Maka diharapkan kebijakan perpajakan yang baru justru dapat meningkatkan pertumbuhan UMKM di seluruh wilayah di Indonesia agar tingkat pengangguran dapat ditekan atau menurun. 
Penelitian (Putri, Saerang, \& Budiarso, 2019) menyatakan sehubungan adanya penurunan tarif SPT $25 \mathrm{PPh}$ Final menjadi 0,5\% tersebut menunjukkan bahwa para pelaku UMKM di Tomohon menunjukkan tingkat kepatuhan yang masih rendah. Di tahun 2019 pemerintah kembali membuat reformasi perpajakan dengan dicabutnya Peraturan Dirjen Pajak Nomor PER-32/PJ/2010 tentang Pelaksanaan Pengenaan Pajak Penghasilan (PPh) Pasal 25 bagi Wajib Pajak Orang Pribadi (WPOP) Pengusaha Tertentu.

Sebagian pelaku UMKM WPOP pengusaha tertentu yang baru memulai usaha akan cenderung lebih memilih menggunakan tarif PPh Final 0,5\% karena alasan kesederhanaan dalam pengenaan pajaknya, yaitu diambil dari peredaran bruto selama sebulan dikalikan 0,5\%. Hal ini sesuai dengan hasil penelitian (Sukarno, Wifasari, \& Setyawan, 2019) yang menyatakan bahwa aturan perpajakan yang lebih sederhana dan mudah untuk dilaksanakan, akan memacu para pelaku UMKM untuk melaksanakan kewajiban perpajakannya. Hal ini sejalan dengan temuan penelitian (Putri et al., 2019) yang menyatakan pemenuhan kewajiban menghitung, membayar dan melaporkan wajib pajak UMKM masih rendah, berbanding terbalik dengan kemauan wajib pajak yang berkemauan untuk melaksanakannya namun terbentur dengan pengetahuan yang seadanya.

Tentu dapat dimaklumi karena para pelaku usaha UMKM yang baru pasti akan mengalami kesulitan dalam menyusun pembukuannya. Namun para pelaku UMKM yang sudah lama akan lebih memilih tarif PPh PPh Pasal 25 Tidak Final sebesar 0,75\% karena pengenaan pajaknya diambil dari penghasilan bersih dikurangi Penghasilan Tidak Kena Pajak (PTKP) selama sebulan. Untuk mendapatkan angka yang tepat dan benar sehubungan penghasilan bersih, dibutuhkan penyusunan pembukuan oleh para pelaku UMKM WPOP Pengusaha Tertentu agar dapat menghitung jumlah PPh 25 Tidak Final setiap bulan yang harus dibayarkan dengan tepat.

\section{Jenis Penelitian}

\section{METODE PENELITIAN}

Jenis penelitian yang digunakan adalah Penelitian Lapangan (Field Research), menurut (Sunyoto, 2013) yaitu penelitian yang dilakukan untuk memperoleh data primer dan data sekunder yaitu dengan observasi. Penulis mengadakan pengamatan secara langsung terhadap masalah apa yang dihadapi, sehingga dari pengamatan tersebut penulis dapat memperoleh data yang akurat dan kongkrit. 
Metode yang digunakan adalah deskriptif kualitatif, menurut (Sugiyono, 2018) Pendekatan deskriptif dalam metode ini dilakukan bertujuan untuk menggambarkan, meringkas kondisi, situasi dan fenomena yang ada pada lingkungan hidup di sekitar masyarakat untuk digunakan sebagai objek penelitian.

(Sugiyono, 2018) mengatakan bahwa: "Metode penelitian kualitatif sering disebut metode penelitian naturalistik karena penelitiannya dilakukan pada kondisi yang alamiah (natural setting); atau disebut juga sebagai metode etnography, karena pada awalnya metode ini lebih banyak digunakan untuk penelitian bidang antropologi budaya; disebut sebagai metode kualitatif, karena data yang terkumpul dan analisisnya lebih bersifat kualitatif".

\section{Lokasi dan Waktu Penelitian}

Lokasi yang digunakan dalam penelitian yaitu wilayah Kota Tangerang Selatan dengan subjek penelitian Orang Pribadi Pengusaha Tertentu pelaku UMKM yang berdomisili Kota Tangerang Selatan dan menggeluti usaha UMKM lebih dari satu tahun. Sedangkan waktu penelitian dimulai pada bulan Agustus 2019 sampai dengan Juli 2020.

\section{Jenis dan Sumber Data}

Sumber data untuk penelitian ini adalah berasal dari dua sumber yaitu sumber data primer dan data sekunder. Dan untuk jenis perolehan data pada penelitian ini adalah dengan Studi Lapangan (Field Research) dan Studi Literatur. Dilakukan menggunakan metode wawancara dengan pihak-pihak yang terkait dengan pembahasan masalah penelitian serta dilakukan mendalam untuk mendapatkan informasi yang diinginkan. Termasuk dengan pihak Kantor Pelayanan Pajak (KPP) Serpong dan KPP Pondok Aren di Wilayah Kota Tangerang Selatan. Sementara studi literatur diperoleh melalui buku dan jurnal penelitian.

\section{Metode Pengumpulan Data}

Adapun data yang diperlukan dalam penelitian ini yaitu :

1. Usaha Mikro, Kecil, dan Menengah yang berada di Kota Tangerang Selatan. Khususnya UMKM yang berada di Wilayah Kecamatan Setu, Serpong, dan Serpong Utara, Pondok Aren, Ciputat, Ciputat Timur dan Pamulang.

2. Teknik pengambilan sampel menggunakan populasi $50 \mathrm{UMKM}$, sehingga jumlah sampel yang diambil sebanyak $30 \%$ dari jumlah populasi yaitu sebanyak 15 UMKM 
pada Wilayah Wilayah Kecamatan Setu, Serpong, dan Serpong Utara, Pondok Aren, Ciputat, Ciputat Timur dan Pamulang.

\section{Teknik Pengambilan Data}

Adalah teknik atau cara-cara yang digunakan oleh peneliti untuk pengumpulan data (Sugiyono, 2018). Dalam penelitian ini, pengambilan data dilakukan dengan cara observasi, wawancara langsung kepada sumber yang sudah ditetapkan dan melakukan dokumentasi. Dengan demikian penelitian ini akan menghasilkan suatu penelitian yang bersifat naturalistic dikarena penelitian yang dilakukan pada kondisi yang alamiah (natural setting), maka dari itu data yang terkumpul dan analisisnya lebih bersifat kualitatif.

\section{Unit Analisis}

Unit analisis adalah satuan tertentu yang diperhitungkan sebagai subjek penelitian. Dalam pengertian yang lain, unit analisis diartikan sebagai sesuatu yang berkaitan dengan fokus/komponen yang diteliti. (Arikunto, 2010). Dalam penelitian ini Unit analisisnya adalah Orang Pribadi Pengusaha Tertentu pelaku bisnis UMKM di Kota Tangerang Selatan.

\section{Teknik Analisis Data}

(Milles, Huberman, \& Saldana, 2014) berpendapat bahwa dalam penelitian kualitatif pada dasarnya analisis data menggunakan pemikiran logis, analisis dengan logika, dengan induksi, deduksi, analogi, komparasi dan sejenisnya. terdapat tiga teknik analisisi data kualitatif yaitu reduksi data, penyajian data dan penarikan kesimpulan.

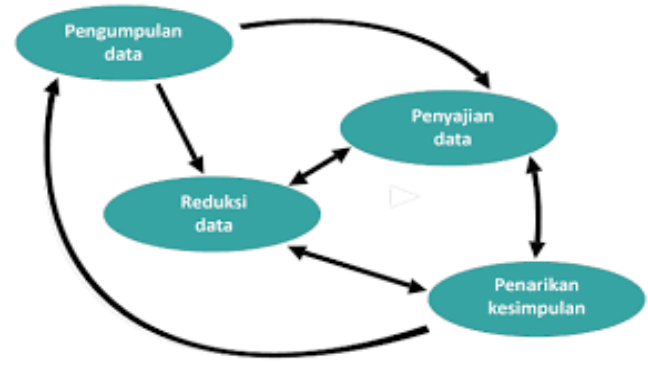

Gambar 1 Teknis Analisis Data Kualitatif Miles dan Huberman (2014) HASIL DAN PEMBAHASAN

Hasil

Penerapan Skema PPh Pasal 25 Atas WPOP Pengusaha Tertentu sesuai PP Nomor 23 Tahun 2018 pada UMKM Kota Tangerang Selatan

Dalam rangka mengetahui penerapan Skema PPh Pasal 25 Atas WPOP Pengusaha Tertentu pelaku UMKM di Kota Tangerang Selatan, maka dapat dilihat berdasarkan 
jumlah wajib pajak yang terdaftar di KPP Pratama Serpong dan KPP Pratama Pondok Aren menggunakan kriteria WPOP Pengusaha Tertentu yang pembukuan dan non pembukuan selama kurun waktu 3 tahun yaitu tahun 2017, 2018, 2019 sesuai dengan tabel berikut ini:

Tabel 1

Data WPOP Pembukuan dan Non Pembukuan Yang terdaftar di KPP Pratama Serpong

\begin{tabular}{|c|c|c|c|c|}
\hline Tahun & $\begin{array}{c}\text { Jumlah } \\
\text { WPOP } \\
\text { Pembukuan }\end{array}$ & $\begin{array}{c}\text { Jumlah } \\
\text { WPOP } \\
\text { Non } \\
\text { Pembukuan }\end{array}$ & Total & $\begin{array}{c}\text { Perbandingan } \\
\text { (\%) }\end{array}$ \\
\hline 2017 & 293 & 1.223 & 1.516 & $\mathbf{4 1 7 , 4 1}$ \\
\hline 2018 & 307 & 1.252 & 1.559 & $\mathbf{4 0 7 , 8 2}$ \\
\hline 2019 & 328 & 1.417 & 1.745 & $\mathbf{4 3 2 , 0 1}$ \\
\hline
\end{tabular}

Sumber: KPP Pratama Serpong 2020

Berdasarkan tabel 1, data WPOP pembukuan dan non pembukuan yang tercatat pada KPP Pratama Serpong selama tahun 2017 sampai dengan 2019 terdapat ketimpangan yang cukup mencolok, yaitu pada tahun 2017 WPOP Pembukuan sebanyak 293 WPOP dan WPOP Non Pembukuan sebanyak 1.223 atau perbandingannya mencapai 417,41\%. Tahun 2018 WPOP Pembukuan sebanyak 307 WPOP dan WPOP Non Pembukuan sebanyak 1.252 atau perbandingannya mencapai 407,82\%. Sedangkan tahun 2019 WPOP Pembukuan sebanyak 328 WPOP dan WPOP Non Pembukuan sebanyak 1.417 atau perbandingannya mencapai $432,01 \%$.

Dari data di atas maka terlihat bahwa terdapat kenaikan yang cukup siqnifikan untuk jumlah WPOP Non pembukuan dibandingkan WPOP Pembukuan. Kita bisa melihat WPOP Non Pembukuan di tahun 2018 meningkat saebanyak 29 WPOP dan di tahun 2019 meningkat sebanyak 165 WPOP, sedangkan untuk WPOP Pembukuan di tahun 2018 hanya naik sebanyak 14 WPOP dan di tahun 2019 naik hanya sebanyak 21 WPOP.

Secara presentase tingkat kenaikan WPOP Pembukuan dapat dilihat pada tabel dibawah ini:

Tabel 2. Tingkat Kenaikan WPOP Pembukuan

\begin{tabular}{|c|c|c|c|}
\hline Tahun & $\begin{array}{c}\text { Jumlah WPOP } \\
\text { Pembukuan }\end{array}$ & $\begin{array}{c}\text { Selisih ke Tahun } \\
\text { Berikutnya }\end{array}$ & $\begin{array}{c}\text { Kenaikan } \\
(\boldsymbol{\%})\end{array}$ \\
\hline 2017 & 293 & - & - \\
\hline 2018 & 307 & 14 & $\mathbf{4 , 7}$ \\
\hline 2019 & 328 & 21 & $\mathbf{6 , 8}$ \\
\hline
\end{tabular}

Sumber: Data KPP Pratama Serpong 2020

Berdasarkan tabel 2, dapat dijelaskan bahwa jumlah WPOP Pengusaha Tertentu yang melakukan pembukuan setiap tahunnya mengalami kenaikan, sesuai data KPP 
Pratama Serpong, Wajib Pajak Orang Pribadi (WPOP) Pengusaha Tertentu yang menyelenggarakan pembukuan mengalami peningkatan dari tahun 2017 yang berjumlah 293 wajib pajak (WP) meningkat di tahun 2018 menjadi 307 WP atau naik sebesar 4,7\% dan dari tahun 2018 ke tahun 2019 sebanyak 328 WP atau naik 6,8\%. Walaupun secara presentase masih terlalu kecil dibandingkan dengan WPOP Non Pembukuan. Sedangkan presentase tingkat kenaikan WPOP Pengusaha Tertentu yang non pembukuan dapat dilihat pada tabel dibawah ini:

Tabel 3. Tingkat Kenaikan WPOP Non Pembukuan

\begin{tabular}{|c|l|l|l|}
\hline Tahun & $\begin{array}{l}\text { Jumlah WPOP } \\
\text { Pembukuan }\end{array}$ & $\begin{array}{l}\text { Selisih ke Tahun } \\
\text { Berikutnya }\end{array}$ & $\begin{array}{l}\text { Kenaikan } \\
(\mathbf{\%})\end{array}$ \\
\hline 2017 & 1.223 & - & - \\
\hline 2018 & 1.252 & 29 & $\mathbf{2 , 4}$ \\
\hline 2019 & 1.417 & 165 & $\mathbf{1 3 , 2}$ \\
\hline
\end{tabular}

Sumber: Data KPP Pratama Serpong 2020

Sesuai tabel 3, data WPOP Pengusaha Tertentu yang non pembukuan yang terdapat pada KPP Pratama Serpong pada tahun 2017 sebesar 1.223 WP dan tahun 2018 sebanyak 1.252 atau naik sebesar 2,4\% sementarara untuk tahun 2019 sebanyak 1.417 WP atau naik dari tahunsebelumnya sebesar 13,2\% sehingga tingkat kenaikannya sedikit lebih tinggi dibandingkan tingkat kenaikan pada Wajiab Pajak Orang Pribadi Pengusaha Tertentu yang pembukuan.

Berlakunya PP No. 23 Tahun 2018 sehubungan penurunan tarif Pajak Final UMKM dari 1\% menjadi 0,5\% pada tanggal 1 Juli 2018 terlihat mempengaruhi secara siqnifikan justru bagi WPOP Non Pembukuan di Wilayah KPP Serpong pada tahun 2019. Ini membuktikan bahwa banyak WPOP Pengusaha Tertentu di Wilayah KPP Serpng justru lebih memilih pembayaran pajaknya menggunakan Pajak Final sebesar 0,5\% persen dari pada menerapkan skema PPh Pasal 25 Tidak Final dengan tarif 0,75\% yang dapat dikreditkan pembayaran pajaknya di akhir tahun.

Sedangkan data yang diperoleh peneliti dari KPP Pratama Pondok Aren adalah seperti terdapat pada tabel berikut ini:

Tabel 4

Data WPOP Pembukuan dan Non Pembukuan Yang terdaftar di KPP Pratama Pondok Aren

\begin{tabular}{|c|c|c|c|c|}
\hline Tahun & $\begin{array}{c}\text { Jumlah } \\
\text { WPOP } \\
\text { Pembukuan }\end{array}$ & $\begin{array}{c}\text { Jumlah } \\
\text { WPOP } \\
\text { Non } \\
\text { Pembukuan }\end{array}$ & Total & $\begin{array}{c}\text { Perbandingan } \\
(\%)\end{array}$ \\
\hline 2017 & 479 & 3.591 & $\mathbf{4 . 0 7 0}$ & $\mathbf{7 4 9 , 7 0}$ \\
\hline 2018 & 443 & 3.783 & $\mathbf{4 . 2 2 6}$ & $\mathbf{8 5 3 , 9 5}$ \\
\hline
\end{tabular}




\begin{tabular}{|l|l|l|l|l|}
\hline 2019 & 445 & 4.207 & $\mathbf{4 . 6 5 2}$ & $\mathbf{1 . 0 4 5 , 3 9}$ \\
\hline
\end{tabular}

Sumber: KPP Pratama Pondok Aren 2020

Jika dilihat pada tabel 4, data WPOP pembukuan dan non pembukuan yang tercatat pada KPP Pratama Pondok Aren selama tahun 2017 sampai dengan 2019 juga terdapat perbedaan yang cukup signifikan, yaitu pada tahun 2017 WPOP Pembukuan sebanyak 479 WPOP dan WPOP Non Pembukuan sebanyak 3.591 atau perbandingannya mencapai 749,70\%. Tahun 2018 WPOP Pembukuan sebanyak 443 WPOP dan WPOP Non Pembukuan sebanyak 3.783 atau perbandingannya mencapai 853,95\%. Sedangkan tahun 2019 WPOP Pembukuan sebanyak 445 WPOP dan WPOP Non Pembukuan sebanyak 4.207 atau perbandingannya mencapai $1.045,39 \%$.

Kita dapat melihat tingkat kenaikan/penurun WPOP Pembukuan yang terdaftar pada KPP Pratama Pondok Aren seperti pada tabel dibawah ini:

Tabel 6 Tingkat Kenaikan WPOP Pembukuan

\begin{tabular}{|c|c|c|c|}
\hline Tahun & $\begin{array}{c}\text { Jumlah WPOP } \\
\text { Pembukuan }\end{array}$ & $\begin{array}{c}\text { Selisih ke } \\
\text { Tahun } \\
\text { Berikutnya }\end{array}$ & $\begin{array}{c}\text { Kenaikan } \\
\text { (\%) }\end{array}$ \\
\hline 2017 & 479 & - & - \\
\hline 2018 & 443 & -36 & $\mathbf{- 7 , 5 \%}$ \\
\hline 2019 & 445 & 2 & $\mathbf{0 , 5 \%}$. \\
\hline
\end{tabular}

Sumber: Data KPP Pratama Pondok Aren 2020

Mencermati tabel 6, sesuai data KPP Pratama Pondok Aren WPOP Pengusaha Tertentu yang menyelenggarakan pembukuan justru mengalami penurunan dari tahun 2017 yang berjumlah 479 WP menurun di tahun 2018 menjadi 443 atau turun sebesar 7,5\% atau turun sebanyak 36 (tiga puluh enam) WPOP dan meningkat sedikit sebanyak 445 di tahun 2019 atau naik sebesar 0,5\% atau sebanyak 2 (dua) WPOP. .

Selanjutnya kita dapat melihat tingkat kenaikan/penurunan WPOP Non Pembukuan yang terdaftar pada KPP Pratama Pondok Aren seperti pada tabel dibawah ini:

Tabel 7. Tingkat Kenaikan WPOP Non Pembukuan

\begin{tabular}{|c|c|c|c|}
\hline Tahun & $\begin{array}{c}\text { Jumlah WPOP Non } \\
\text { Pembukuan }\end{array}$ & $\begin{array}{c}\text { Selisih ke } \\
\text { Tahun } \\
\text { Berikutnya }\end{array}$ & $\begin{array}{c}\text { Kenaikan } \\
(\mathbf{\%})\end{array}$ \\
\hline 2017 & 3.591 & - & - \\
\hline 2018 & 3.783 & 192 & $\mathbf{5 , 3 5}$ \\
\hline 2019 & 4.207 & 424 & $\mathbf{1 0 , 0 8}$ \\
\hline
\end{tabular}

Sumber: Data KPP Pratama Pondok Aren 2020

Berdasarkan tabel 7, KPP Pratama Pondok Aren mencatat WPOP Pengusaha Tertentu Non Pembukuan tahun 2017 yang berjumlah 3.591 wajib pajak dan tahun 2018 sebanyak 3.783 wajib pajak atau naik sebesar 5,35\% atau sebanyak 192 WPOP serta di 
tahun 2019 sebesar 4.207 wajib pajak atau naik sebesar 10,08\% atau sebanyak 424 WPOP..

Berlakunya PP No. 23 Tahun 2018 sehubungan penurunan tarif Pajak Final UMKM dari 1\% menjadi 0,5\% pada tanggal 1 Juli 2018 terlihat mempengaruhi secara siqnifikan justru bagi WPOP Non Pembukuan di Wilayah KPP Pondok Aren baik di tahun 2018 dan tahun 2019. Ini membuktikan bahwa banyak WPOP Pengusaha Tertentu di Wilayah KPP Pondok Aren langsung bereaksi terhadap berlakunya PP No. 23 Tahun 2018. Mereka memilih pembayaran pajaknya menggunakan Pajak Final sebesar $0,5 \%$ persen dari pada menerapkan skema PPh Pasal 25 Tidak Final dengan tarif 0,75\% dan biusa dikreditkan pembayaran pajakanya di akhir tahun.

Maka berdasarkan data yang tersaji dari masing-masing tabel diatas, wajib pajak masih banyak yang mengabaikan pentingnya pembukuan dalam menjalankan usahanya, karena rata-rata dari Wajib Pajak Orang Pribadi Pengusaha Tertentu pelaku UMKM bukan berlatarbelakang ilmu akuntansi, serta merasa enggan ketika harus menggunakan pembukuan.

Berlakunya Peraturan Pemerintah (PP) Nomor 23 Tahun 2018 yang berlaku di bulan Juli 2018 yang didalamnya mengatur penurunan tarif PPh Final dari dari 1\% menjadi 0,5\% memberikan kesempatan kepada setiap wajib pajak untuk dapat dengan mudah menghitung pajak terutangnya, tanpa harus menyusun laporan keuangan karena hanya dengan mengalikan antara omzet per bulan dengan tarif $0,5 \%$.

Dengan demikian sesuai data di atas, Penerapan Skema PPh Pasal 25 Atas WPOP Pengusaha Tertentu sesuai PP Nomor 23 Tahun 2018 pada UMKM Kota Tangerang Selatan yang terdaftar di KPP Pratama Serpong dan KPP Pratama Pondok Aren tidak maksimal karena wajib pajak cenderung menggunakan tarif PPh Final 0,5\%, hal tersebut dapat diketahui dari presentase perbandingan antara yang menyelenggarakan pembukuan sebagai dasar dalam menggunakan $\mathrm{PPh}$ tarif umum ( $\mathrm{PPh}$ Pasal $31 \mathrm{E}$ ) yang digunakan sebagai dasar perhitungan dalam melakukan pembayaran angsuran pajak setiap bulan menggunakan PPh Pasal 25 dibandingkan dengan WPOP Pengusaha tertentu yang tidak menyelenggarakan pembukuan.

Efektifitas Peningkatan Kepatuhan Perpajakan WPOP Pengusaha Tertentu Melalui Penerapan Skema PPh Pasal 25 Sesuai PP Nomor 23 Tahun 2018 Pada UMKM Kota Tangerang Selatan 
Peningkatan kepatuhan WPOP Pengusaha Tertentu dalam melaksanakan kewajiban perpajakannya dapat dilihat dari tingkat pembayaran dan tingkat penyampaian SPT Tahunan.

Dimulai dari data penerimaan pajak yang diperoleh dari KPP Pratama Serpong selama tahun 207, 2018 da 2019.

\section{Tabel 8}

Data Penerimaan Pajak KPP Pratama Serpong

Tahun 2017-2019

\begin{tabular}{|c|c|c|c|}
\hline Tahun & $\begin{array}{c}\text { WPOP PT PPh } \\
\text { Pasal 25(Rp) }\end{array}$ & WPOP PT PPh Final (Rp) & Total (Rp) \\
\hline 2017 & 20.373 .283 .353 & 14.127 .930 .877 & 34.501 .214 .230 \\
\hline 2018 & 17.887 .930 .121 & 17.641 .705 .143 & 35.529 .635 .264 \\
\hline 2019 & 16.866 .742 .658 & 21.382 .228 .370 & 38.248 .971 .028 \\
\hline Total & $\mathbf{5 5 . 1 2 7 . 9 5 6 . 1 3 2}$ & $\mathbf{5 3 . 1 5 1 . 8 6 4 . 3 9 0}$ & $\mathbf{1 0 8 . 2 7 9 . 8 2 0 . 5 2 2}$ \\
\hline
\end{tabular}

Sumber: KPP Pratama Serpong

Berdasarkan data pada Tabel 8, total tingkat penerimaan pajak dari WPOP yang tercatat di KPP Pratama Serpong setiap tahun selalu mengalamai kenaikan. Namun dilihat dari klasifikasi berdasarkan skema pembayaran PPh nya maka dapat dilihat bahwa dari WPOP yang menggunakan Skema PPh Pasal 25 mengalami tren penurunan setiap tahunnya. Hal ini disebabkan oleh beberapa faktor salah satunya adalah terkendala sumberdaya manusia yang menguasai pembukuan. Seperti perolehan pajak tahun 2017 sebesar Rp 20.373.283.353 menurun di tahun 2018 sebesar Rp 17.887.930.121 atau turun senilai $\operatorname{Rp} 2.485 .353 .232$ dan ditahun 2019 sebesar Rp 16.866.742.658 atau turun senilai Rp 1.021.187.463.

Sebaliknya penerimaan pajak dari WPOP yang menggunakan Skema PPh Final justru mengalami tren kenaikan. Hal itu terlihat dari perolehan di tahun 2017 sebesar 14.127.930.877 dan tahun 2018 sebesar Rp 17.641.705.143 atau naik senilai Rp 3.513.774.266 lalu perolehan tahun 2019 sebesar Rp 21.382.228.370 atau naik senilai $\mathrm{Rp}$ 3.740.523.227. Namun sayangnya nilai penerimaan ini tidak dipisahkan antara WPOP Pengusaha Tertentu dengan WPOP lainnya, jadi penerimaan yang bersifat global.

Dengan berlakunya PP No. 23 Tahun 2018 pada tanggal 1 Juli 2018 justru terdapat kejadian yang kontras, dimana jumlah penerimaan Pajak di Wilayah KPP Serpong untuk WPOP yang memilih PPh Pasal 25 atau Pajak Tidak Final atau Pembukuan, penerimaan pemnbayaran pajaknya terus menurun baik di tahun 2018 maupun di tahun 2019. Sedangkan untuk WPOP yang memilih Pajak Final terlihat naik terus baik di tahun 2018 
dan di tahun 2019. Hal ini menunjukkan terdapat pengaruh yang sangat siqnifikan terhadap berlakunya PP No. 23 tahun 2018 yang menurunkan tarifnya dari 1\% menjadi 0,5\%. Jadi WPOP Pengusaha Tertentu langsung bereaksi terhadap keuntungan penurunan tarif ini. Bisa jadi terdapat WPOP PT Pembukuan yang beralih dari menggunakan pembukuan ke non pembukuan di Wilayah KPP Serpong.

Sementara dari data pelaporan SPT Tahunan yang tercatat pada KPP Pratama Serpong dapat dilihat pada tabel dibawah ini:

Tabel 9. Data Pelaporan SPT Tahunan WPOP PT Skema PPh 25

\begin{tabular}{|c|c|c|c|}
\hline Keterangan & 2017 & 2018 & 2019 \\
\hline WP Lapor & 178 & 219 & 241 \\
\hline WP Tdk Lapor & 115 & 88 & 87 \\
\hline Jumlah & 293 & 307 & 328 \\
\hline Tingkat Kepatuhan & $60,75 \%$ & $71,33 \%$ & $\mathbf{7 3 , 4 8 \%}$ \\
\hline
\end{tabular}

Sumber: KPP Pratama Serpong, 2020

Berdasarkan tabel 9, data pelaporan SPT Tahunan dari WPOP Pengusaha Tertentu pengguna Skema PPh 25 yang melaksanakan kewajiban perpajakannya lebih tinggi dibanding yang tidak melaksanakan kewajiban perpajakannnya sekaligus mengalami kenaikan setiap tahunnya, seperti data tahun 2017 WPOP Lapor sebanyak 178 wajib pajak dan WPOP Tidak Lapor sebanyak 115, tingkat kepatuhan mencapai 60,75\%, lalu tahun 2018 WPOP Lapor sebanyak 219 dan WPOP Tidak Lapor sebanyak 88 atau tingkat kepatuha mencapai 71,33\% sedangkan data tahun 2019 WPOP Lapor sebanyak 241 wajib pajak dan WPOP Tidak Lapor sebanyak 87, atau tingkat kepatuhan mencapai 73,48\%. Sementara data pelaporan SPT Tahunan dari WPOP Pengusaha Tertentu pengguna Skema PPh Final seperti terlihat pada tabel dibawah ini:

Tabel 10. Data Pelaporan SPT Tahunan WPOP PT Skema PPh Final 0,5\%

\begin{tabular}{|l|c|c|c|}
\hline \multicolumn{1}{|c|}{ Keterangan } & $\mathbf{2 0 1 7}$ & $\mathbf{2 0 1 8}$ & $\mathbf{2 0 1 9}$ \\
\hline WP Lapor & 362 & 407 & 530 \\
\hline WP Tdk Lapor & 861 & 845 & 887 \\
\hline Jumlah & $\mathbf{1 . 2 2 3}$ & $\mathbf{1 . 2 5 2}$ & $\mathbf{1 . 4 1 7}$ \\
\hline \multicolumn{1}{|c|}{ Tingkat Kepatuhan } & $\mathbf{2 9 , 6 0 \%}$ & $\mathbf{3 2 , 5 0 \%}$ & $\mathbf{3 7 , 4 0 \%}$ \\
\hline
\end{tabular}

Sumber: KPP Pratama Serpong, 2020

Dilihat dari tabel 10. Data pelaporan SPT Tahunan dari WPOP Pengusaha Tertentu pengguna Skema PPh Final ternyata justru mengalalmi tingkat penurunan yang signifikan. yang melaksanakan kewajiban perpajakannya lebih rendah dibanding yang tidak 
melaksanakan kewajiban perpajakannnya dan setiap tahun mengalami penurunan yang cukup drastis, seperti data tahun 2017 WPOP Lapor sebanyak 362 wajib pajak dan WPOP Tidak Lapor sebanyak 861, tingkat kepatuhan hanya 29,60\% lalu tahun 2018 WPOP Lapor sebanyak 407 dan WPOP Tidak Lapor sebanyak 845 atau tingkat kepatuhan 32,50\% sedangkan data tahun 2019 WPOP Lapor sebanyak 530 wajib pajak dan WPOP Tidak Lapor sebanyak 887, atau tingkat kepatuhan 37,40\%.

Jadi tingkat kepatuhan pajak untuk WPOP yang menyelenggarakan Pembukuan lebih tinggi atau lebih baik dari pada WPOP yang Non Pembukuan di Wilayah KPP Serpong, baik di tahun 2017, 2018 dan 2019. Hal ini menunjukkan bahwa penerapan pembukuan pada WPOP Pengusaha Tertentu di Wilayah KPP Serpong turut membantu dalam melaksanakan kepatuhan pelaporan SPT WPOP di akhir tahun.

Sementara itu data penerimaan pajak pada KPP Pratama Pondok Aren dapat dilihat dari tabel berikut ini:

\section{Tabel 11}

Data Penerimaan Pajak KPP Pratama Pondok Aren

Tahun 2017-2019

\begin{tabular}{|c|c|c|c|}
\hline Tahun & $\begin{array}{c}\text { WPOP PT PPh } \\
\text { Pasal 25 }\end{array}$ & WPOP PT PPh Final & Total \\
\hline 2017 & 7.356 .076 .370 & 10.541 .564 .536 & 17.897 .640 .906 \\
\hline 2018 & 10.982 .327 .745 & 10.407 .418 .370 & 21.389 .746 .115 \\
\hline 2019 & 12.583 .383 .503 & 8.748 .829 .416 & 21.332 .212 .919 \\
\hline Total & 30.921 .787 .618 & 29.697 .812 .322 & 60.619 .599 .940 \\
\hline
\end{tabular}

Sumber: KPP Pratama Pondok Aren.2020

Sesuai data pada tabel 11, tingkat penerimaan pajak dari WPOP yang tercatat di KPP Pratama Pondok Aren yang menggunakan Skema PPh Pasal 25 mengalami tren kenaikan setiap tahunnya. Sedangkan berdasarkan skema pembayaran PPh final justru mengalami tren penurunan. Hal ini dapat dilihat dari perolehan pajak berdasrkan Skema PPh Pasal 25 tahun 2017 sebesar Rp 7.356.076.370 naik di tahun 2018 sebesar Rp 10.982.327.745 atau naik senilai $\mathrm{Rp}$ 3.626.251.375 dan ditahun 2019 sebesar Rp 12.583.383.503 atau naik senilai $\mathrm{Rp} 1.601 .055 .758$.

Sementara penerimaan pajak dari WPOP yang menggunakan Skema PPh Final terlihat dari perolehan di tahun 2017 sebesar 10.541.564.536 dan tahun 2018 sebesar Rp 10.407.418.370 atau turun senilai Rp 134.146.166 lalu perolehan tahun 2019 sebesar Rp 8.748.829.416 atau turun senilai Rp 1.658.588.954.

Dengan berlakunya PP No. 23 Tahun 2018 pada tanggal 1 Juli 2018 di Wilayah KPP Pondok Aren justru terjadi sebaliknya dengan yang terjadi di Wilayah KPP Serpng dimana untuk 
WPOP yang memilih PPh Pasal 25 atau Pajak Tidak Final atau Pembukuan, penerimaan pembayaran pajaknya terus naik sejak tahun 2017, 2018 dan 2019. Sedangkan untuk WPOP yang memilih Pajak Final terlihat terus menurun sejak tahun 2017, 2018 dan tahun 2019. Hal ini menunjukkan tidak terdapat pengaruh yang siqnifikan terhadap kepatuhan WPOP PT Pembukuan terhadap berlakunya PP No. 23 tahun 2018 yang menurunkan tarifnya dari $1 \%$ menjadi $0,5 \%$ di Wilayah KPP Pondok Aren. Jadi WPOP Pengusaha Tertentu Pembukuan tidak beralih dari menggunakan pembukuan ke non pembukuan di Wilayah KPP Pondok Aren.

Tabel 12. Data Pelaporan SPT Tahunan WPOP PT Skema PPh 25

\begin{tabular}{|c|c|c|c|}
\hline Keterangan & 2017 & 2018 & 2019 \\
\hline WP Lapor & 419 & 397 & 413 \\
\hline WP Tdk Lapor & 60 & 46 & 32 \\
\hline Jumlah & 479 & 443 & 445 \\
\hline Tingkat Kepatuhan & $87,47 \%$ & $89,61 \%$ & $\mathbf{9 2 , 8 0 \%}$ \\
\hline
\end{tabular}

Sumber: KPP Pratama Pondok Aren. 2020

Berdasarkan tabel 12. Data pelaporan SPT Tahunan dari WPOP Pengusaha Tertentu pengguna Skema PPh 25 yang melaksanakan kewajiban perpajakannya lebih tinggi dibanding yang tidak melaksanakan kewajiban perpajakannnya sekaligus mengalami kenaikan setiap tahunnya, seperti data tahun 2017 WPOP Lapor sebanyak 419 wajib pajak dan WPOP Tidak Lapor sebanyak 60, tingkat kepatuhan mencapai 87,47\%, lalu tahun 2018 WPOP Lapor sebanyak 397 dan WPOP Tidak Lapor sebanyak 46 atau tingkat kepatuha mencapai 89,61\% sedangkan data tahun 2019 WPOP Lapor sebanyak 413 wajib pajak dan WPOP Tidak Lapor sebanyak 32, atau tingkat kepatuhan mencapai 92,80\%

Tabel 12. Data Pelaporan SPT Tahunan

WPOP PT Skema PPh Final 0,5\%

\begin{tabular}{|l|c|c|c|}
\hline \multicolumn{1}{|c|}{ Keterangan } & $\mathbf{2 0 1 7}$ & $\mathbf{2 0 1 8}$ & $\mathbf{2 0 1 9}$ \\
\hline WP Lapor & 2.329 & 1.541 & 894 \\
\hline WP Tdk Lapor & 1.262 & 1.242 & 3.313 \\
\hline Jumlah & $\mathbf{3 . 5 9 1}$ & $\mathbf{3 . 7 8 3}$ & $\mathbf{4 . 2 0 7}$ \\
\hline \multicolumn{1}{|c|}{ Tingkat Kepatuhan } & $\mathbf{6 4 , 8 5 \%}$ & $\mathbf{4 0 , 7 3 \%}$ & $\mathbf{2 1 , 2 5 \%}$ \\
\hline
\end{tabular}

Sumber: KPP Pratama Pondok Aren

Berdasarkan tabel 12, data pelaporan SPT Tahunan dari WPOP Pengusaha Tertentu pengguna Skema PPh Final ternyata cukup fluktuaktif. seperti data tahun 2017 WPOP Lapor sebanyak 2.329 wajib pajak dan WPOP Tidak Lapor sebanyak 1.262, tingkat kepatuhan mencapai 64,85\% kemudian tahun 2018 WPOP Lapor sebanyak 1.541 dan WPOP Tidak Lapor sebanyak 1.242 atau tingkat kepatuhan $40,73 \%$ atau mengalami 
penurunan sedangkan data tahun 2019 WPOP Lapor sebanyak 894 wajib pajak dan WPOP Tidak Lapor sebanyak 3.313, atau tingkat kepatuhan 21,25\%.

Menurut data KPP Pratama Pondok Aren WPOP Pengusaha Tertentu yang menyelenggarakan pembukuan justru mengalami penurunan dari tahun 2017 yang berjumlah 479 WP menurun di tahun 2018 menjadi 443 dan meningkat sedikit sebanyak 445 di tahun 2019. Perilaku WPOP Pengusaha tertentu di KPP Pondok Aren bertolak belakang dengan perilaku WPOP Pengusaha Tertentu di KPP Pratama Serpong, dimana terdapat 7,5\% yang beralih menerapkan PPh Final 0,5\% di tahun 2018 dan sebanyak menipis sedikit menjadi 7,1\% penurunannya di tahun 2019.

Jadi tingkat kepatuhan pajak untuk WPOP yang menyelenggarakan Pembukuan juga lebih tinggi atau lebih baik dari pada WPOP yang Non Pembukuan di Wilayah KPP Pondok Aren, baik di tahun 2017, 2018 dan 2019. Dengan angka yang sangat baik di atas 87\%. Hal ini menunjukkan bahwa penerapan pembukuan pada WPOP Pengusaha Tertentu di Wilayah KPP Pondok Aren juga turut membantu dalam melaksanakan kepatuhan pelaporan SPT WPOP di akhir tahun.

Dengan demikian efektifitas peningkatan kepatuhan perpajakan WPOP Pengusaha Tertentu melalui penerapan skema PPh Pasal 25 sesuai PP Nomor 23 Tahun 2018 pada UMKM Kota Tangerang Selatan sesuai dengan hasil penelitian menjadi tidak efektif, karena WPOP Pengusaha Tertentu pelaku UMKM cenderung memilih memanfaatkan kemudahan yang berikan pemerintah melalui PP 23 Tahun 2018 dengan menggunakan tarif PPh Final 0,5\% dalam melakukan perhitungan pajaknya daripada menggunakan tarif umum yang kemudian digunakan sebagai dasar untuk menentukan angsuran PPh Pasal 25.

\section{KESIMPULAN}

1. WPOP Pengusaha Tertentu pelaku UMKM yang tercatat di KPP Pratama Serpong dan KPP Pratama Pondok Aren yang memanfaatkan penurunan tarif $1 \%$ menjadi 0,5\% mulai bulan Juli 2018 sesuai yang tercantum dalam PP No. 23 Tahun 2018 (tidak menyelenggarakan pembukuan), mengalami peningkatan. Sedangkan hal sebaliknya terjadi pada penggunaan skema tarif $\mathrm{PPh} 25$ yang mengalami penurunan setiap tahunnya. Hal ini dikarenakan wajib pajak tidak harus menyampaikan laporan keuangan sebagai dasar pelaporan pajaknya, namun cukup menghitung pajak terutangnya dengan cara mengalikan omzet perbulan dengan tarif PPh Final 0,5\%.

2. Penerapan Skema PPh Pasal 25 Atas WPOP Pengusaha Tertentu sesuai PP Nomor 
23 Tahun 2018 pada UMKM Kota Tangerang Selatan yang terdaftar di KPP Pratama Serpong dan KPP Pratama Pondok Aren tidak maksimal karena tidak menjadi pilihan utama bagi wajib pajak, walaupun pembayaran atas $\mathrm{PPh}$ Pasal 25 dapat dikreditkan pada akhir tahun pajak hal tersebut dapat diketahui dari presentase perbandingan antara yang menyelenggarakan pembukuan sebagai dasar dalam menggunakan $\mathrm{PPh}$ tarif umum (PPh Pasal 31 E) dengan WPOP Pengusaha tertentu yang tidak menyelenggarakan pembukuan atau menggunakan tarif PPh Final 0,5\%.

3. WPOP Pengusaha Tertentu pelaku UMKM cenderung memilih memanfaatkan kemudahan yang berikan pemerintah melalui PP 23 Tahun 2018 dengan menggunakan tarif PPh Final 0,5\% dalam melakukan perhitungan pajaknya daripada menggunakan tarif umum yang kemudian digunakan sebagai dasar untuk menentukan angsuran PPh Pasal 25. Dengan demikian efektifitas peningkatan kepatuhan perpajakan WPOP Pengusaha Tertentu melalui penerapan skema $\mathrm{PPh}$ Pasal 25 sesuai PP Nomor 23 Tahun 2018 pada UMKM Kota Tangerang Selatan sesuai dengan hasil penelitian menjadi tidak efektif.

\section{DAFTAR PUSTAKA}

Arikunto, S. (2010). Prosedur Penelitian Ilmiah. Jakarta: Rineka Cipta.

Goso, \& Bachri, S. (2015). Implementasi Pemberdayaan Usaha Ekonomi Mikro Kecil Dan Menengah (UMKM). Jurnal Manajemen STIEM Palopo, 02(01), 1-10.

Ikbal, M., Mustafa, S. W., \& Bustami, L. (2018). Peran Usaha Mikro, Kecil Dan Menengah Dalam Mengurangi Pengangguran Di Kota Palopo. Jurnal Ekonomi Pembangunan STIE Muhammadiyah Palopo, 4(1), 35-46. https://doi.org/10.35906/jep01.v4i1.293

Milles, M. B., Huberman, M. A., \& Saldana, J. (2014). Qualitative Data Analysis A methods Sourcebook Edition 3 (Terjemahan Tjetjep Rohindi Rohidi). In Sage Publications, Inc.

Movanita, A. N. K. (2019). Dari Hampir 60 Juta UMKM, Baru 1,8 Juta Terdaftar sebagai Wajib Pajak.

Putri, T., Saerang, D. P. E., \& Budiarso, N. S. (2019). Analisis Perilaku Wajib Pajak Umkm Terhadap Pelaksanaan Pemungutan Pajak Dengan Menggunakan Self Assessment System Di Kota Tomohon. Going Concern: Jurnal Riset Akuntansi, 14(1), 130-136. https://doi.org/10.32400/gc.14.1.22321.2019

Suci, R. P., Hermawati, A., \& Suwarta. (2019). Pentingnya Analisis Swot Untuk Meningkatkan Kinerja SDM (Studi Kasus Usaha Mikro Kecil dan Menengah Malang). Jurnal Manajemen STIEM Palopo, 5(2), 24-27. 
Sugiyono. (2018). Metode Penelitian Kuantitatif,Kualitatif dan R\&D. Ke-26.

Sukarno, Wifasari, S., \& Setyawan, B. (2019). Upaya Peningkatan Penerimaan Pajak Melalui Penjualan Berbasis E Commerce Pada UMKM Kota Tangerang Selatan. Jurnal Mitra Manajemen, 3(9), 903-917.

Sunyoto, D. (2013). Manajemen Sumber Daya Manusia. Yogyakarta: CAPS (Center Of Academic Publishing Service). 